DOI 10.20396/temáticas.v24i47/48.11115

\title{
A GREVE DAS UNIVERSIDADES FEDERAIS E OS DESAFIOS DE MOBILIZAÇÃO NA PÓS-GRADUAÇÃO
}

\author{
João Pedro de Lima Campos ${ }^{1}$
}

RESUMO: Neste artigo apresento um relato crítico sobre a greve de estudantes, docentes e trabalhadores da Universidade Federal Fluminense (UFF) no ano de 2015 a partir da discussão sobre os desafios de mobilização na pós-graduação. Essa greve aconteceu no marco dos primeiros cortes orçamentários realizados ainda no início do segundo mandato da presidenta Dilma Rousseff, que afetou o equilíbrio financeiro das reitorias, resultando em atraso no pagamento de salários e bolsas. Para entendermos através de que mecanismos a redução do repasse impacta a universidade federal, analisamos a relação existente entre a greve de 2015 e o processo de desmonte do programa de Reestruturação e Expansão das Universidades Federais (REUNI), razão medular para a organização da luta política relatada. Apresento também as lições aprendidas em um cenário de severos ataques à universidade pública a fim de apontar soluções para o problema da organização dos alunos de pós-graduação, que historicamente não conseguem se articular em defesa dos próprios interesses.

PALAVRAS-CHAVE: Greve estudantil; Pós-graduação; REUNI.

\section{APRESENTAÇÃO}

Em maio de 2015 foi deflagrada greve na Universidade Federal Fluminense (UFF). Tal medida veio como reação aos cortes orçamentários do governo federal no montante destinado ao custeamento

\footnotetext{
${ }^{1}$ Mestre em Sociologia pela Universidade Federal Fluminense (UFF-RJ). E-mail: camposjpl@ gmail.com
} 
do ensino superior no país. Uma após a outra, as três categorias da universidade - discentes, docentes e funcionários - votaram, em assembleia, a favor da mobilização e deram início a uma greve que durou 131 dias.

Quase um ano após seu término ${ }^{2}$, a perspectiva ainda é de cortes e de ameaça ao futuro das universidades públicas no país. Apresento neste texto um breve relato da recente e persistente conjuntura político -orçamentária de uma universidade federal e os desafios que nós, estudantes de mestrado e doutorado, encontramos ao nos mobilizarmos durante essa greve que como não podia deixar de ser - nos afetou diretamente.

\section{A GREVE DE 2015 NA UFF}

Após o anúncio do bloqueio de $1 / 3$ no repasse de verbas para as universidades federais no início do segundo mandato da então presidenta Dilma Rousseff, a ordem do dia para os reitores era economizar. ${ }^{3}$ Sem dinheiro em caixa para arcar com seus compromissos, a Reitoria atrasou o pagamento de bolsas, deixou trabalhadores terceirizados sem salários, suspendeu obras em novos prédios ${ }^{4}$ e mesmo algo tão fundamental quanto o fornecimento de energia elétrica foi ameaçado. ${ }^{5}$

O impacto da crise orçamentária das universidades públicas foi primeiro sentido pelos trabalhadores terceirizados da limpeza, alimentação, manutenção predial e segurança, que já vinham realizando paralisações pontuais devido aos constantes atrasos no pagamento dos salários que já ocorriam antes do anúncio de cortes pelo Ministério da Educação (MEC) ${ }^{6}$.

\footnotetext{
${ }^{2} \mathrm{O}$ artigo foi redigido em setembro de 2016.

${ }^{3}$ MEC bloqueia um terço da verba das federais; universidades atrasam bolsas. Disponível em: http://ultimosegundo.ig.com.br/educacao/2015-02-25/mec-bloqueia-um-terco-da-verbadas-federais-universidades-atrasam-bolsas.html. Acesso em: 30 ago. 2016.

${ }^{4}$ Sem verbas federais, UFF mergulha na crise. Disponível em: http://oglobo.globo.com/rio/ sem-verbas-federais-uff-mergulha-na-crise-17256420. Acesso em: 30 ago. 2016.

${ }^{5}$ Corte no orçamento da UFF chega a $\mathrm{R} \$ 20$ milhões em 2015 e afeta funcionamento dos cursos. Disponívelem: http://oglobo.globo.com/rio/bairros/corte-no-orcamento-da-uffchega-r-20-milhoes-em-2015-afeta-funcionamento-dos-cursos-16307386. Acesso em: 30 ago. 2016.

${ }^{6}$ Aulas são canceladas na UFF por greve de funcionários terceirizados; salários estão atrasados
} 
Longe de ser uma questão exclusiva da UFF, o atraso no pagamento de salários dos funcionários terceirizados foi um fenômeno geral nas universidades do Rio de Janeiro naquele ano. A situação financeira e política na UERJ, UFRJ e UNIRIO - sediadas na capital do estado - estava tão problemática quanto na federal de Niterói ${ }^{7}{ }^{8}$, de modo que o movimento dos trabalhadores terceirizados assumia um caráter interinstitucional em que uma mobilização impulsionava a outra através de manifestações e atividades conjuntas.

Esses trabalhadores pertencem à categoria mais precarizada na universidade, cujos contratos são elaborados sob a luz da flexibilização das leis trabalhistas que fragiliza o emprego e expõe o funcionário ao constante risco da demissão. Enquanto para os trabalhadores concursados da universidade a greve representa um instrumento de luta política e de proteção ao emprego, para os terceirizados ela significa, com sorte, a ameaça de desconto do vencimento na folha de pagamento; sem sorte, a greve resulta em retorno à larga fila do desemprego. Por isso a corda dos cortes arrebenta para o lado dos terceirizados, a classe com mais dificuldade de organização política dentro da universidade ${ }^{9}$ e por isso mais exposta à ameaça da demissão.

No entanto, naquele ano a situação de atraso de salários se tornou alarmante e generalizada em um nível que mesmo esse setor politicamente vulnerável se mobilizou. Em defesa de seus direitos e afirmando que trabalhador terceirizado não é escravo, os funcionários cruzaram os braços. Inicialmente ocorreram paralisações pontuais em março e abril

desde dezembro. Disponível em: http://extra.globo.com/noticias/educacao/aulas-saocanceladas-na-uff-por-greve-de-funcionarios-terceirizados-salarios-estao-atrasados-desdedezembro-15617777.html. Acesso em: 30 ago. 2016.

${ }^{7}$ Cortes orçamentários geram crise nas universidades do Rio. Disponível em: http://exame. abril.com.br/brasil/noticias/cortes-orcamentarios-geram-crise-nas-universidades-do-rio. Acesso em: 30 ago. 2016.

${ }^{8}$ Sem pagamento de terceirizados, UERJ sofre com o acúmulo de lixo. Disponível em: http:/ / g1.globo.com/rio-de-janeiro/noticia/2015/04/sem-pagamento-de-terceirizados-uerj-sofrecom-acumulo-de-lixo.html. Acesso em: 30 ago. 2016.

9 GRANZOTTO, Tânia M. A implementação de ações neoliberais nas Universidades Públicas. Disponível em: http://periodicos.sbu.unicamp.br/ojs/index.php/sss/article/ view/8634830/2749. Acesso em: 30 ago. 2016.. 
até que houve a deflagração da greve dos terceirizados em maio, afetando diretamente toda comunidade acadêmica, cujo cotidiano foi arrastado para o efeito da mobilização diante da falta dos serviços de alimentação, segurança e manutenção predial.

Neste contexto, a precarização da educação superior através de cortes orçamentários já era sentida em todos os setores na universidade, e à medida que elementos simples, porém básicos para a vida cotidiana no campus desapareciam, ficava clara a urgência de mobilização: copos e guardanapos foram cortados do restaurante universitário, ao invés de suco, apenas água; nada de azeite ou farinha de mandioca na mesa; faltou papel higiênico e sabão nos banheiros; elevadores foram desligados; paralisou-se obras de infra-estrutura e delegou-se para um futuro incerto a ampliação da insípida moradia que possui apenas trezentas vagas em um universo de mais de cinquenta mil alunos ${ }^{10}$.

Em um dos momentos mais críticos durante a greve, a UFF teve o fornecimento de energia elétrica suspenso por falta de pagamento à fornecedora. Foi necessária a intervenção da Justiça Federal para normalizar a situação através de uma ação judicial que obrigava a empresa Ampla S.A. - responsável pela energia elétrica em Niterói - a religar a luz na universidade, sob o argumento de que se tratava de um serviço fundamental ${ }^{11}$; a Federal Fluminense é, afinal, uma das maiores universidades federais em número de alunos.

Esse episódio marcou um dos grandes momentos de mobilização, expondo que a paralisação era inevitável em um contexto em que, mesmo sem aulas, e, portanto, com economia de gastos, a universidade não conseguia manter-se em funcionamento. A própria reitoria reconheceu, através de nota oficial, o equilibrismo orçamentário que realizava e responsabilizava a política de ajustes do governo federal como responsável

\footnotetext{
${ }^{10}$ Federais enfrentam crise por alojamento. Disponível em: http://odia.ig.com.br/noticia/ rio-de-janeiro/2015-05-24/federais-enfrentam-crise-por-alojamento.html. Acesso em: 30 ago. 2016.

11 Após suspender fornecimento de energia, Justiça Federal proíbe corte de luz na UFF. Disponível em: http://oglobo.globo.com/rio/apos-suspender-fornecimento-de-energiajustica-federal-proibe-corte-de-luz-na-uff-17286522. Acesso em: 30 ago. 2016.
} 
pela situação de crescente caos na qual a UFF se encontrava ${ }^{12}$.

A deterioração da universidade federal iniciada pelo contingenciamento de verbas de 2015 , e que continua em curso, envolveu todas as categorias. Trabalhadores sem salários, alunos sem bolsa e com acesso restrito aos serviços fundamentais do campus, professores sobrecarregados com o aumento da relação aluno/professor e sem a perspectiva de ampliação do corpo docente. Nesse cenário, apenas dois meses após o início do ano letivo, a UFF estava completamente paralisada.

\section{O DESMONTE DO REUNI E A PRECARIZAÇÃO DO ENSINO SUPERIOR PÚBLICO}

Estive nas assembleias de cada um dos três setores quando foi votada a greve. Minha surpresa foi grande ao assistir o corpo docente votar massivamente pela construção dessa mobilização; situação que nunca havia presenciado durante meus anos de graduação na Unicamp, onde, de modo geral, os professores se mostram bastantes contrários à greve.

Tal fenômeno se explica, em parte, pelo fato de que nas universidades federais existe, atualmente, um número expressivo de professores recém contratados, jovens, que ainda buscam estabilidade profissional e crescimento na carreira acadêmica e se mostram dispostos a defender e lutar em defesa da categoria. Esses docentes ingressaram nas Instituições Federais de Ensino Superior (IFES) durante o processo de expansão do ensino universitário chamado de REUNI - Reestruturação e Expansão das Universidades Federais. Trata-se de uma política educacional iniciada ainda no segundo mandato do governo Lula, no ano de 2007, que alterou intensamente o aspecto das universidades federais.

Em linhas gerais, o REUNI significou uma rápida expansão no número de vagas nas IFES, tendo em vista a inclusão de setores historicamente excluídos do ensino superior, como as populações PPI

\footnotetext{
${ }^{12}$ Nota da Universidade Federal Fluminense sobre o corte de luz. Disponível em: http:/ /www. uff.br/?q=nota-da-universidade-federal-fluminense-sobre-o-corte-de-luz. Acesso em: 30 ago. 2016.
} 
(pretos, pardos e indígenas) ${ }^{13}$ e a população mais pobre, sem a contrapartida da exclusão de setores que tradicionalmente ingressam nessas instituições. Com o aumento no número de alunos, veio a demanda pela ampliação das políticas de permanência estudantil, de assistência social e psicológica aos estudantes, que em nenhum momento foi atendida; desde sua origem, o contraponto da expansão foi a ameaça de precarização. Não obstante as fragilidades do projeto, o REUNI cumpriu papel importante ao enfatizar o caráter social das universidades federais e contribuir para a ampliação do número de programas de pós-graduação e incentivar a produção científica no país. Com o anúncio de cortes a partir de 2015, esse projeto estava - e continua - ameaçado.

O pano de fundo da greve na UFF foi, portanto, uma resposta aos indícios de deterioração do REUNI, que foi percebido e expressado de forma distinta pelas três categorias da universidade. A pauta mais urgente para os alunos de graduação dizia respeito a políticas de permanência estudantil e bolsas de pesquisa, pois, se por um lado, a população negra e pobre havia conseguido ingressar no ensino superior durante os anos do governo do Partido dos Trabalhadores (PT), por outro, sua continuidade nos estudos não estava garantida, pois a contradição entre ampliação de vagas e corte de verbas resulta em evasão. Já em 2014, o percentual de alunos que abandonaram o curso de graduação na UFF era de 17,4\%; muito superior aos $11 \%$ da UFSCAR ou aos $8,2 \%$ da UFU. Ainda assim, a Federal Fluminense apresenta uma taxa de conclusão superior às das outras três federais do Rio de Janeiro ${ }^{14}$, o que aponta quão problemática está a situação nesse estado.

A greve de 2015 conduzida pelas três categorias não dizia respeito apenas à defesa de salários, condições de trabalho e estudo, ela estava intrinsecamente ligada ao desmonte de um projeto político em vigência há

13 REUNI - Reestruturação e Expansão das Universidades Federais. Diretrizes Gerais. Disponível em: http://portal.mec.gov.br/sesu/arquivos/pdf/diretrizesreuni.pdf. Acesso em: 30 ago. 2016.

14 Série histórica evasão e conclusão nas IFES. Disponível em: http://www.uff.br/sites/ default/files/serie_historica_evasao_e_conclusao.pdf. Acesso em: 30 ago. 2016. 
quase uma década. Por essa razão, as atuais demandas da universidade não podiam ser respondidas sem passar pela discussão do caráter da instituição e do futuro do REUNI, que se ligava não apenas a UFF em particular, mas a todas as federais - pois a crise que enfrentamos na Federal Fluminense é apenas um braço - talvez um dos mais expostos - de uma crise conjuntural no sistema federal de ensino superior.

A reação contundente dos alunos de graduação veio em 26 de maio daquele ano, quando, dois dias antes do início da greve dos trabalhadores, os estudantes reunidos em assembleia votaram pela ocupação do prédio da reitoria contra os cortes e atrasos nas bolsas, por ampliação da moradia, permanência estudantil e em solidariedade às demais categorias ${ }^{15}$. Enquanto durou a ocupação da reitoria, que também abriga uma sala de cinema, um teatro e uma galeria de arte, nós estudantes tivemos intenso contato com os funcionários do prédio, ocasião em que percebemos nossos objetivos comuns e nossos conflitos e discordâncias sobre perspectivas para a universidade; pois, ainda que as três categorias em greve tivessem o mesmo interesse em preservar a qualidade do ensino e afirmar o caráter público da instituição, surgiram divergências sobre como esse fim seria alcançado, questões sobre método de luta política que se expressavam sobretudo quando o debate dizia respeito ao futuro incerto do REUNI.

Junto de novos alunos, a expansão da universidade significou a contratação de novos funcionários, trabalhadores que ascenderam ao serviço público estável através das políticas do governo federal para a educação. À medida que os alunos de graduação expunham em assembleia a fragilidade do REUNI e a necessidade de se criticar a política educacional do PT, os funcionários defendiam as conquistas que o processo de expansão representou. Vinha à tona diferenças políticas entre as três categorias, entre servidores recém contratados e aqueles com vínculos antigos com a UFF e entre esses e uma juventude recém chegada à universidade, com anseios de permanência e mais ampliação.

\footnotetext{
${ }^{15}$ Alunos da UFF ocupam reitoria após anúncio de greve nesta quinta. Disponível em: http:/ / g1.globo.com/rio-de-janeiro/noticia/2015/05/alunos-da-uff-ocupam-reitoria-apos-anunciode-greve-nesta-quinta.html. Acesso em: 30 ago. 2016.
} 


\section{OS DESAFIOS DA MOBILIZAÇÃO NA PÓS-GRADUAÇÃO}

Apesar das divergências entre professores, trabalhadores e estudantes acerca da crítica ao REUNI, a greve atravessou o primeiro semestre e quase chegou ao fim do ano. Apenas a pesquisa continuou na UFF. Não obstante o contexto excepcional em que nos encontrávamos, nós estudantes de pós-graduação não paramos nossas atividades.

No decorrer de minha primeira greve estudantil como aluno de pós-graduação, vivi todos os limites e barreiras que encontramos para nos mobilizar. Fosse pela falta de representatividade e articulação da Associação Nacional dos Estudantes de Pós-Graduação (ANPG), pela pressão dos prazos exigidos pelas agências de fomento ou pela indisposição dos professores em alterar o cronograma de aulas, o fato era que a pós-graduação na UFF se mostrou como um setor bastante alienado do contexto político que o cercava.

Duas semanas após o início da greve nós alunos de Sociologia nos reunimos com professores e coordenadores do programa para debater a possibilidade de tirarmos um posicionamento conjunto enquanto curso, e as alternativas de mobilização que possuíamos. Nesse momento, nenhum docente opôs resistência à ideia de aderirmos à greve; um ou outro até se mostrou simpático à proposta. No entanto, apesar do respeito à nossa tentativa de organização, nenhum argumento era mais forte que a palavra prazo, continuamente proferida pelos docentes e pesquisadores dos vários programas pós-graduação.

De modo algum nos era vetada a paralisação, ou a alternativa de entrar em greve, não apenas em solidariedade com as outras categorias, mas em defesa de nossos próprios interesses. A postura dos nossos professores não foi declaradamente de oposição ao processo político que atravessávamos; o tom, porém, era de alerta: mesmo em greve, os prazos permaneciam inalterados.

Nossa mobilização precisava, então, encontrar meios de agir sem prejudicar o andamento de nossas pesquisas. Isolados enquanto curso, tomamos de empréstimo os exemplos de outros programas de pósgraduação, que redigiram cartas públicas em defesa da greve e tomaram 
parte no movimento ao tirar alguns dias de paralisação como indicativo de greve. Não fomos, porém, além disso.

Longe de ser um problema individual de alunos específicos, ou que diga respeito apenas a um curso mais ou menos mobilizado, o que enfrentamos em 2015 na pós-graduação de Sociologia da UFF perpassa a realidade de pesquisadores em todo país. Somos regidos pelas mesmas regras seja no Amapá, Rio de Janeiro ou Mato Grosso do Sul. As diferentes agências de fomento possuem normas semelhantes, são igualmente inflexíveis na ampliação de prazos e exercem pressão sobre os professores para que esses - como gerentes de produção - mantenham a pesquisa de seus alunos em dia. Para nós, estudantes de pós-graduação, não era o corte o carrasco mais direto, mas a ameaça de perdermos nossas bolsas ou termos nosso estudo inviabilizado devido aos prazos.

Durante quatro meses frequentei o campus vazio e senti as implicações da greve. Durante quatro meses encontrei fechados o restaurante universitário, as salas de informáticas, as áreas de lazer e, também, o que é mais flagrante, a biblioteca. A questão que permanece é como é possível desenvolver uma pesquisa sem acesso aos livros, ao ambiente de estudo e ao serviço de informática? Como manter uma rotina saudável na universidade sem o convívio com os demais estudantes mobilizados?

Por trás dos prazos das agências de fomento existe a realidade da precarização da pós-graduação que coloca os alunos em um verdadeiro malabarismo acadêmico quando a greve estoura. Sob a palavra prazo está oculta a luta cotidiana de estudantes que, mesmo que queiram, dificilmente podem aderir integralmente a um movimento político em curso na universidade. O prazo, elevado a semideus da academia e aliado ao produtivismo, se torna fator de precarização das pesquisas; o prazo, em um contexto de greve, é símbolo exposto da contradição entre a produção científica e as condições em que ela é realizada.

Diante dos prazos, nós, estudantes de Sociologia, optamos por uma paralisação de um dia - apenas um dia! - e por redigir um texto em apoio ao movimento dos trabalhadores, estudantes e professores. Isolados em um grupo de quinze alunos, continuamos nosso estudo de Sociologia, 
ironicamente desligado do ambiente que nos cercava. Foi bastante artificial frequentar uma sala de aula em um prédio onde não havia mais ninguém, exceto os funcionários responsáveis por abrir e fechar o edifício e manter a mínima limpeza. Desses recebemos olhares descontentes; não lhes tiro a razão.

Ao longo do período da greve discutimos bastante em nossa turma o que fazer; e não foi difícil chegar a conclusão de que nos faltava articulação com outros programas de pós-graduação de nossa universidade e de outras, pois sempre que uma greve se inicia enfrentamos o mesmo problema de desmobilização. Logo ali na cidade do Rio de Janeiro três federais passavam pela mesma situação e os alunos de pós-graduação compartilhavam conosco os mesmos problemas; e ainda que os terceirizados tenham dado exemplo de união interinstitucional ao realizarem atos conjuntos na capital, nós pós-graduandos nunca nos comunicamos, sobretudo porque delegamos ações e decisões a ANPG, órgão pouco presente no cotidiano dos alunos e que durante o processo de greve tentou influenciar no processo político, sem ser capaz de representar nossos reais interesses.

Nesse cenário em que assistimos a greve desfilar perante nosso curso de mestrado e atravessar completamente nossa vida acadêmica, perguntamo-nos insistentemente qual seria a maneira correta de responder aos desafios colocados a mobilização na pós-graduação a partir da experiência na UFF? Se a pós-graduação possui uma dinâmica própria - e é certo que possui - orientada por cronogramas e prazos, torna-se requisito básico para nossa greve discutir e negociar tais prazos. Nenhum programa sozinho tem força o bastante para pressionar as agências de fomento, bem como um único curso de graduação paralisado não incomoda a reitoria. A conclusão nada inédita a que se chega é a da necessidade de uma organização que efetivamente defenda os interesses dos pós-graduandos, e possibilite que o aluno mobilizado não seja prejudicado por sua posição política.

Continuamos em nossa rotina extraordinária até outubro de 2015, quando a greve chegou ao fim. Nós pós-graduandos a atravessamos e, apesar de muito sentirmos seu efeito no cotidiano, tivemos de continuar em aula. A reitoria conseguiu fechar seu ano orçamentário - à custa de 
muita precarização do restaurante universitário e da estrutura dos prédios - e em março de 2016 o ano letivo anterior foi encerrado. Ao contexto dos cortes federais somou-se a falência do estado do Rio de Janeiro que também afeta a UFF, mesmo que indiretamente, dando continuidade a uma crise que, superado seu momento mais agudo, se mantém como um estado permanente em nossas vidas acadêmicas e cotidianas.

A realidade de cortes ainda permanece, a demanda por assistência estudantil cresce e a pós-graduação em Sociologia, a despeito do que passou em 2015, continua desmobilizada. É claro que esse não é um problema local, mas se estende por toda a UFF, passa pelas outras universidades federais do Rio de Janeiro e alcança os outros estados.

O aprendizado central dessa greve foi que nós, estudantes de pós-graduação, dificilmente nos enxergamos enquanto uma categoria na universidade, premidos que estamos entre a formação, o ensino e pesquisa - e a nossa dificuldade de mobilização se deve muito a essa percepção errônea de que nossos interesses e formas de luta são os mesmos dos graduandos ou dos docentes. Conduzimos nossas pesquisas individualmente, estamos submetidos à pressão dos prazos e para cumprilos nos mantemos isolados em bibliotecas - quando elas estão abertas - e conforme nos afastamos da graduação, nos tornamos mais distantes da articulação política estudantil.

É certo que as mesmas questões que apresentei neste breve relato estiveram presentes durante a greve de 2016 na Unicamp, que acompanhei a distância e me levaram a redigir este texto. A resistência dos pesquisadores à greve e a desconfiança e o medo de perder os prazos ecoa nos alunos daqui como nos de lá. Por isso, é importante enfatizar que nós, estudantes de pós-graduação, somos uma categoria com interesses próprios e formas particulares de se organizar para a greve, embora dificilmente percebemos com clareza a unidade que compomos. A própria estrutura de nossos cursos de mestrado e doutorado nos isola uns dos outros e à medida que nos aprofundamos em nossas pesquisas facilmente nos alienamos da política que se desenrola em nosso ambiente.

Até que consigamos pressionar coletivamente, enquanto uma categoria, as agências CAPES, FAPESP, FAPEMIG, CNPQ, FAPERJ, 
etc., continuaremos presos à lógica produtivista de entrega de artigos, teses e dissertações no prazo, sem levar em conta a real situação que a universidade atravessa. O lado sinistro de nossa desarticulação se reflete na falta de resposta a nossas demandas: ampliação do número de bolsas, contratação de docentes que implica em aumento de linhas de pesquisa, acesso a material de alta qualidade ou mesmo a possibilidade de negociação de ampliação de prazos quando necessário. Por fim, após meu primeiro ano de mestrado e diante de toda a vida acadêmica por percorrer, percebo que aos pós-graduandos falta o reconhecimento político-institucional enquanto uma categoria, que nos tiraria do limbo que surge entre os interesses da graduação e as demandas da docência e pesquisa. 